\title{
Substitution of Sucrose in Lassi by Tagatose as a Sweetener
}

\author{
Akashamrut M. Patel ${ }^{1}$, Subrota Hati ${ }^{2}$, Bhavbhuti M. Mehta ${ }^{3}$ and K.D. Aparnathi ${ }^{3}$ \\ ${ }^{1}$ Department of Food Safety \& Testing, College of FPT \& BE, AAU, Anand, India \\ ${ }^{2}$ Department of Dairy Microbiology, SMC College of Dairy Science, AAU, Anand, India \\ ${ }^{3}$ Department of Dairy Chemistry, SMC College of Dairy Science, AAU, Anand, India \\ *Corresponding author: max037.ndri@gmail.com
}

Received: $17-03-2021$

Revised: 24-05-2021

Accepted: $15-06-2021$

\begin{abstract}
In the era of reduction in sugar consumption, availability of suitable alternative sweeteners is highly desirable. But to find an ideal substitute of sucrose remained destined dream. Tagatose is now is emerging as very promising substitute of sucrose for use as a sweetener. Therefore, in present study suitability of tagatose evaluated as a sweetener in Lassi. The findings of the study suggested that Lassi prepared by substituting sucrose by tagatose or its blend with sucrose or fructose was very well acceptable in sensory evaluation. Tagatose was able to substitute sucrose in Lassi without any changing the process parameter. Proximate composition, physicochemical properties and microbial counts of the sucrose substituted Lassi were more or less similar to corresponding products prepared by using sucrose as a sweetener. Shelf-life of the sucrose substituted Lassi was also similar to corresponding Lassi prepared by using sucrose as a sweetener.
\end{abstract}

Keywords: Tagatose, Lassi, Substitution, Sucrose

Sweeteners got entry in to food industry and became staple in foodstuffs. Due to progress in production of refined sugar from raw sources, it became possible to add sweetness to food. Among the sweeteners, humans are most accustomed to disaccharide sucrose. Sugar elicit a sweet taste but energy dense diets high in sugars contribute to excess calorie intake, which in turn leads to obesity with concomitant health problems. Therefore, reduction in consumption of sugar has become an important goal.

Substitution of sucrose and other nutritive sweeteners with alternative non-calorie/low-calorie and highintensity sweeteners is practical approach to achieve this goal. However, sucrose is considered as gold standard for sweetness (WHO, 2017). None of the alternative sweetener up to now seems to be perfect in view of the requirements for an ideal sugar substitute, because sucrose possesses unique combinations of physical, chemical and microbiological properties for its key role in sweetened products. Therefore, it poses unique challenges in its substitution in different types products (Davis, 1995). Consequently, producing a high-quality food product using alternatives to sugar is not straightforward. Hence, total sucrose replacement may remain pipe dream forever (Hutchings et al. 2019).

In selection of suitable alternative sweeteners for substitution of sucrose, the sweetener is judged on various facets: naturalness, glycemic index, calorie count and any positive effect on nutrition they may bring (Martí et al. 2008; Streak, 2015).

How to cite this article: Patel, A.M., Hati, S., Mehta, B.M. and Aparnathi, K.D. (2021). Substitution of Sucrose in Lassi by Tagatose as a Sweetener Intl. J. Ferment. Food, 10(1): 25-34.

Source of Support: None; Conflict of Interest: None (क) 
Tagatose is reported as a natural sweetener with functional attributes. In recent years it has received increasing attention from food industry and scientific community. D-tagatose (or tagatose) is a mirror image of $\mathrm{D}$-fructose at the fourth carbon atom (Vastenavond et al. 2012). Although tagatose is naturally occurring in some fruits and dairy products (Skytte 2006), it is commercially produced from lactose through chemical and/or enzymatic processes (Vastenavond et al. 2012). The resulting tagatose has sweetness characteristics highly resembling to those of sucrose (Fujimaru et al. 2012). Moreover, many physical and chemical characteristics of tagatose are also very similar to those of the sucrose (Levin et al. 1995; Levin 2002; Kim, 2004; Lu et al. 2008). Tagatose has been generally recognized as safe (GRAS) for use in foods and beverages by FDA (FDA 2011).

Fortunately, now tagatose is emerging as a potential alternative low calorie full bulk sweetener due to its (a) relative sweetness almost equivalent to sucrose, (b) sweetness characteristics very closely resembling to sucrose (c) low glycemic index, (d) low calorie content and (e) similarity in application related technological properties such as bulk, browning, etc.. Moreover, it has functional nature, which makes the tagatose different from other low-calorie sweeteners. It is regarded as a tooth-friendly substance. The unabsorbed tagatose acts as prebiotic (Bertelsen et al. 2001; Venema et al. 2005). The prebiotic activity of tagatose was well preserved in food products even after thermal treatments (Luecke \& Bell 2010).

Though tagatose is emerging as promising substitute of sucrose, information on its application and suitability in various categories of dairy products is very limited. In India, among sweetened fermented dairy products, Lassi is the most popular and widely consumed traditional Indian dairy product all throughout the country. Therefore, from the category of fermented milk products Lassi was selected to try substitution of sucrose by tagatose as a sweetener.

\section{MATERIALS AND METHODS}

The tagatose of sweet health brand from Natural, USA brand was procured from local supplier of ingredients. The content (purity) of tagatose was 100 per cent. Sucrose of Madhur brand from "Shree Renuka Sugars Limited" was procured from local market. Content (purity) of sucrose was 99.4 per cent. Fructose of "Lobachemie" brand was purchased from local supplier. Content (purity) of fructose was 99 per cent. Microbial culture: Cultures Streptococcus thermophilus (MTCC 5460) and Lactobacillus helveticus (MTCC 5463) were obtained from Dairy Microbiology Department of this college.

\section{Preparation of Lassi}

For preparation of Lassi, Amul brand toned milk containing 3 per cent fat and 8.5 per cent SNF was used. The Lassi available in Indian market usually contains 12 per cent sucrose (Aneja et al. 2002; De, 2001). In industrial production of Lassi, addition of sucrose is reported at the rate of 12 per cent (Ranganadham, 2016). Therefore, in this study for preparation of Lassi sucrose was added at rate of 12 per cent.

Lassi was prepared using method as reported by Aneja et al. (2002). The milk was heated to $90^{\circ} \mathrm{C}$ for 10 minutes. After cooling milk to $40^{\circ} \mathrm{C}$ mixed culture (Streptococcus thermophilus (MTCC 5460) and Lactobacillus helveticus (MTCC 5463), in ratio of 1:1) was inoculated at the rate of 1 per cent and incubated for 12 hours at $42^{\circ} \mathrm{C}$. After incubation sweetener and water were added to give sweetness and reduce viscosity. Product was stirred to smooth uniform consistency. Addition of water was kept fixed at 20 per cent by weight of curd. Samples of Lassi were prepared using tagatose alone, blend of tagatose + sucrose, blend of tagatose + fructose and sucrose alone as sweeteners. The amount of each sweetener used in preparation of Lassi is given in Table 1. The selection of these sweeteners and their rate of addition are based on the work carried out by Patel et al. (2021) for optimization of sucrose substitution in Lassi using tagatose as an alternative sweetener. 
Table 1: Amount of sweeteners used in preparation of Lassi

\begin{tabular}{ll}
\hline Sweetener & Amount used (g/100 ml Lassi) \\
\hline Tagatose & 14.40 \\
Tagatose + Sucrose & $10.80+3.00$ \\
Tagatose + Fructose & $12.96+1.44$ \\
Sucrose & 12.00 \\
\hline
\end{tabular}

Analysis of Lassi for proximate composition

Total solids (TS) fat, protein and ash were determined by gravimetric method as described by BIS (1981). Total carbohydrates where estimated by difference method in which sum total of percentage of other constituents in product was subtracted from 100 .

\section{Analysis of Lassi for physico-chemical characteristics}

Specific gravity of Lassi was determined at $30^{\circ} \mathrm{C}$ using specific gravity bottle using method as described by BIS (1981). Viscosity of Lassi was determined at $30^{\circ} \mathrm{C}$ using Brookfield DV-II + Pro viscometer. Method provided by manufacture was followed for determining viscosity of Lassi (Brookfield Engineering Laboratories). Acidity of Lassi was determined by titration method as suggested by reported by BIS (1981).

\section{Analysis of Lassi for microbial counts}

Lassi was analyzed for coliform count as well as yeast and mold counts (YMC). For the microbial counts methods suggested by BIS (1981) were used.

\section{Sensory evaluation of Lassi}

Sensory evaluation of flavoured milk, Lassi was carried out for their overall acceptability using 9 point hedonic scale according to the method suggested by Wichchukit \& O'Mahony (2015). The evaluation was carried out by a panel of experienced judges. The score given by different judges was averaged out. The average values were compiled and used for statistical analysis and reported here.

\section{Shelf life evaluation of Lassi}

Samples of Lassi were filled in PET bottles, stored in refrigerator at $6^{\circ} \pm 1^{\circ} \mathrm{C}$ and analyzed for changes in acceptability in sensory evaluation and acidity at an interval of $24 \mathrm{~h}$ (i.e. every day).

\section{Statistical analysis of data}

The mean values of each of the attributes in the study were subjected to statistical analysis using Completely Randomized Design. The statistical model adopted was given by Steel and Torrie (1980) which is illustrated as given below:

$$
Y_{i j}=m+T_{i}+E_{i j}
$$

Where,

$Y_{i j}=$ Response due to $j^{\text {th }}$ observation in the $i^{\text {th }}$ treatment. $m=$ general mean

$T_{i}=$ effect of $i^{\text {th }}$ treatment, and

$E_{i j}=$ Error due to $j^{\text {th }}$ observation in the $i^{\text {th }}$ treatment.

\section{RESULTS AND DISCUSSION}

Lassi prepared using different sweetener was proximate composition, relevant physico-chemical properties, microbial counts and acceptance in sensory evaluation.

\section{Proximate Composition of Lassi}

For proximate composition, Lassi prepared using $14.4 \mathrm{~g}$ tagatose $(\mathrm{T}), 12.0 \mathrm{~g}$ sucrose $(\mathrm{S})$, blend of 10.8 $\mathrm{g}$ tagatose $+3.0 \mathrm{~g}$ sucrose $(\mathrm{T}+\mathrm{S})$ and blend of 12.96 $\mathrm{g}$ tagatose $+1.44 \mathrm{~g}$ fructose $(\mathrm{T}+\mathrm{F})$ per $100 \mathrm{ml}$ Lassi as sweeteners was analyzed for total solids (TS), fat, protein carbohydrates (CHOs) and ash content. Proximate composition of the Lassi and its statistical analysis are summarized in the Table 2.

\section{Total solids content of Lassi}

Total solids content of Lassi with different sweeteners varied from 22.06 to 24.10 per cent. The highest total solids content was found in Lassi prepared using tagatose alone as a sweetener, very closely followed by the Lassi prepared using the blend of tagatose and fructose. The lowest total solids content was found in Lassi prepared using sucrose alone as a sweetener, followed by the Lassi prepared using sucrose alone 
Table 2: Proximate composition of Lassi prepared using different sweeteners

\begin{tabular}{|c|c|c|c|c|c|c|c|}
\hline \multirow{2}{*}{\multicolumn{2}{|c|}{ S1. No. Sweetener used }} & \multirow{2}{*}{$\begin{array}{l}\text { \% Sucrose } \\
\text { substitution }\end{array}$} & \multicolumn{5}{|c|}{ Constituent (\%) } \\
\hline & & & TS & Fat & Protein & CHOs & Ash \\
\hline 1 & $\mathrm{~T}$ & 100 & $24.10^{\mathrm{b}}$ & 1.95 & 2.28 & 19.35 & 0.51 \\
\hline 2 & $\mathrm{~T}+\mathrm{S}$ & 75 & $23.61^{\mathrm{b}}$ & 2.04 & 2.36 & 18.69 & 0.52 \\
\hline 3 & $\mathrm{~T}+\mathrm{F}$ & 100 & $24.07^{\mathrm{b}}$ & 1.92 & 2.34 & 19.29 & 0.52 \\
\hline 4 & S & 0 & $22.06^{\mathrm{a}}$ & 2.10 & 2.41 & 17.02 & 0.53 \\
\hline \multicolumn{8}{|c|}{ ANOVA } \\
\hline \multicolumn{3}{|l|}{ SEm. } & 0.21 & 0.05 & 0.09 & 0.21 & 0.01 \\
\hline \multicolumn{3}{|l|}{$\mathrm{CD}$} & 0.92 & - & - & 0.87 & - \\
\hline \multicolumn{3}{|l|}{ Test $_{(0.05)}$} & * & NS & NS & * & NS \\
\hline \multicolumn{3}{|l|}{$\mathrm{CV} \%$} & 1.86 & 4.82 & 7.45 & 2.22 & 2.51 \\
\hline
\end{tabular}

There was statistically significant difference in total solids and total carbohydrates content of Lassi, whereas fat, protein and ash content of Lassi were statistically at par.

as a sweetener, and that prepared using the blend of tagatose and sucrose. The differences in total solids content were attributed to differences in rate of additions of sweeteners between these samples.

The total solids content of all the samples of Lassi were very well in accordance the values reported in the literature (Bagal et al. 2007; Bhoir et al. 2012; Ranganadham et al. 2016; Khupse et al. 2017; Upadhyay et al. 2017; Mule et al. 2018).

\section{Fat content of Lassi}

Fat content of Lassi with different sweeteners varied from 1.92 to 2.04 per cent. The differences in fat content of Lassi prepared using different sweeteners appeared very narrow and were proportionate to differences in their total solids content.

In literature the fat content in Lassi is reported from 1.02 to 4.70 per cent (Bagal et al. 2007; Bhoir et al. 2012; Ranganadham et al. 2016; Khupse et al. 2017; Upadhyay et al. 2017). Therefore, the fat content of Lassi were very well in accordance the values reported in the literature.

\section{Protein content of Lassi}

Protein content of Lassi with different sweeteners varied from 2.28 to 2.41 per cent. The differences in protein content of Lassi prepared using different sweeteners appeared very narrow and were proportionate to differences in their total solids content.

In literature the protein content in Lassi is reported from 1.71 to 3.59 per cent (Bhoir et al. Khupse et al. 2017; Pallavi et al. 2020; Upadhyay et al. 2017; Mule et al. 2018). Therefore, the protein content of Lassi were very well in accordance the values reported in the literature.

\section{Total carbohydrates content of Lassi}

Total carbohydrates content of Lassi with different sweeteners varied from 17.02 to 19.35 per cent. The highest total carbohydrates content was found in Lassi prepared using tagatose alone as a sweetener, very closely followed by the Lassi prepared using the blend of tagatose and fructose. The lowest total carbohydrates content was found in Lassi prepared using sucrose alone as a sweetener, followed by the Lassi prepared using sucrose alone as a sweetener, and that prepared using the blend of tagatose and sucrose. The differences in total carbohydrates content were attributed to differences in rate of additions of sweeteners between these samples.

In literature the carbohydrates content in Lassi is reported from 12.60 to 17.40 per cent (Bhoir et al. 2012; Khupse et al. 2017; Pallavi et al. 2020; Upadhyay et al. 2017; Mule et al. 2018; Shuwu et al. 2011). Therefore, the carbohydrates content of Lassi was in accordance 
the values reported in the literature. Somewhat higher carbohydrates content in tagatose containing samples was attributed its relatively greater amount added to generally use in preparation of Lassi reported in various studies.

\section{Ash content of Lassi}

Ash content of Lassi with different sweeteners varied from 0.51 to 0.53 per cent. The differences in ash content of Lassi prepared using different sweeteners appeared very narrow. Slightly higher ash content of Lassi prepared with sucrose alone as a sweetener might be due to relatively higher ash content of sucrose compared to that of the tagatose.

In literature the ash content in Lassi is reported from 0.41 to 0.70 per cent (Bhoir et al. Khupse et al. 2017; Pallavi et al. 2020; Upadhyay et al. 2017). Therefore, the ash content of Lassi were very well in accordance the values reported in the literature.

\section{Physico-chemical Properties of Lassi}

For physico-chemical properties, Lassi prepared using $14.4 \mathrm{~g}$ tagatose $(\mathrm{T}), 12.0 \mathrm{~g}$ sucrose $(\mathrm{S})$, blend of $10.8 \mathrm{~g}$ tagatose $+3.0 \mathrm{~g}$ sucrose $(\mathrm{T}+\mathrm{S})$ and blend of $12.96 \mathrm{~g}$ tagatose $+1.44 \mathrm{~g}$ fructose $(\mathrm{T}+\mathrm{F})$ per $100 \mathrm{ml}$ Lassi as sweeteners was analyzed for specific gravity, viscosity, and acidity. Average results of specific gravity, viscosity, and acidity from four replications are presented in Table 3.

\section{Specific gravity of Lassi}

Specific gravity of Lassi with different sweeteners varied from 1.08 to 1.088 at $30^{\circ} \mathrm{C}$. The highest specific gravity was found in Lassi prepared using the blend of tagatose and fructose as a sweetener, very closely followed by the Lassi prepared using tagatose alone. Thelowest specific gravity was found in Lassi prepared using sucrose alone as a sweetener, followed by the Lassi prepared using blend of sucrose and tagatose as a sweetener. The differences in specific gravity were attributed to differences in their total solids contents, because changes in specific gravity was proportionate variation in total solids content of Lassi.

According to Deshpande et al. (2020) specific gravity of Lassi varied from 1.065 to 1.070. Therefore, the specific gravity of Lassi prepared using sucrose as sweetener in present study was in close proximity the values reported by these authors. The specific gravity of Lassi prepared using tagatose as sweetener was somewhat higher compared to the reported value, due its higher rate of addition than that of the sucrose.

\section{Viscosity of Lassi}

Viscosity of Lassi with different sweeteners varied from 284.4 to $312 \mathrm{mPs}$ at $30^{\circ} \mathrm{C}$. The highest viscosity was found in Lassi prepared using the blend of tagatose and fructose as a sweetener, very closely followed by the Lassi prepared using tagatose alone.

Table 3: Physico-chemical properties of Lassi prepared using different sweeteners

\begin{tabular}{llllll}
\hline Sl. No. & Sweetener used & $\begin{array}{l}\text { \% Sucrose } \\
\text { substitution }\end{array}$ & Specific gravity & Viscosity (mPa $\mathbf{s})$ & $\begin{array}{l}\text { Acidity (\% lactic } \\
\text { acid) }\end{array}$ \\
\hline 1 & $\mathrm{~T}$ & 100 & $1.088^{\mathrm{b}}$ & 308.3 & 0.68 \\
2 & $\mathrm{~T}+\mathrm{S}$ & $1.085^{\mathrm{ab}}$ & 303.6 & 0.69 \\
3 & $\mathrm{~T}+\mathrm{F}$ & $1.089^{\mathrm{b}}$ & 312.4 & 0.68 \\
4 & $\mathrm{~S}$ & 0 & $1.080^{\mathrm{a}}$ & 284.4 & 0.70 \\
\hline & & ANOVA & & 0.024 \\
\hline SEm. & & 0.002 & 8.21 & - \\
\hline $\mathrm{CD}$ & & 0.007 & - & $\mathrm{NS}$ \\
\hline Test & & $*$ & $\mathrm{NS}$ & 6.82 \\
\hline $\mathrm{CV} \%$ & & 0.052 & 5.46 & \\
\hline
\end{tabular}

There was statistically significant difference in specific gravity of Lassi, whereas viscosity and acidity of Lassi were statistically at par. 
The lowest viscosity was found in Lassi prepared using sucrose alone as a sweetener, followed by the Lassi prepared using blend of sucrose and tagatose as a sweetener. The differences in viscosity were attributed to differences in their total solids contents, because changes in specific gravity was proportionate variation in total solids content of Lassi.

In literature the wide variation in viscosity of Lassi is reported. The reported values are ranging from 136 to 363.2 cp (Dixit, 2018; Kaur et al. 2019; Mule et al. 2018; Ranjan et al. 2015). Therefore, the viscosity of Lassi were very well in accordance the values reported in the literature.

\section{Acidity of Lassi}

Acidity of Lassi with different sweeteners varied from 0.68 to .70 per cent lactic acid. Therefore it is evident that there very narrow differences in acidity of Lassi prepared using different sweeteners. The sweeteners were added after completing the step of fermentation involved in preparation of Lassi. Therefore, effect of sweeteners on acidity of Lassi is not expected.

In literature the wide variation in acidity of Lassi is reported. The reported values are ranging from 0.43 to 1.15 per cent. (Bagal et al. 2007; Bhoir et al. 2012; Deshpande et al. 2020; Kaur et al. 2019; Khupse et al. 2017; Mule et al. 2018; Upadhyay et al. 2017). Therefore, the viscosity of Lassi were very well in accordance the values reported in the literature.

\section{Microbial Counts of Lassi}

Microbial analysis of the Lassi was carried for coliform count as well as yeast and mold count. In enumeration of microbial counts of Lassi, only Lassi prepared using tagatose alone and sucrose alone as sweeteners were included, since these were two extreme cases among four types of sweeteners. Total three replications were conducted. Results of the microbial counts of Lassi are presented in Table 4.

The results of the microbial counts suggested that SPC, coliform as well yeast and mold count in Lassi fulfilled the requirements laid down by FSSAI for fermented milk products under Microbiological Standards for Milk and Milk Products -Process Hygiene Criteria (FSSAI, 2019).

\section{Acceptability of Lassi in sensory evaluation}

For evaluating acceptability Lassi was prepared using

Table 4: Microbial counts of Lassi prepared using different sweeteners

\begin{tabular}{llll}
\hline S1. No. & Sweetener used $(\mathbf{g} / \mathbf{1 0 0} \mathbf{~ m l})$ & Coliform $(\mathbf{c f u} / \mathbf{g})$ & Yeast \& mold $(\mathbf{c f u} / \mathbf{g})$ \\
\hline 1 & Tagatose $(14.40)$ & Absent & $1.33 \pm 0.88$ \\
2 & Sucrose $(12.00)$ & Absent & $2.33 \pm 0.33$ \\
\hline
\end{tabular}

Table 5: Overall acceptability score of Lassi prepared using different sweeteners

\begin{tabular}{|c|c|c|c|}
\hline Sl. No. & $\begin{array}{l}\text { Rate of sucrose substitution } \\
(\%)\end{array}$ & $\begin{array}{l}\text { Sweetener \& its amount used } \\
(\mathrm{g} / 100 \mathrm{ml})\end{array}$ & $\begin{array}{l}\text { Acceptability score } \\
\text { (out of 9) }\end{array}$ \\
\hline 1 & 100 & Tagatose (14.40) & 8.41 \\
\hline 2 & 75 & Tagatose $(10.80)+$ Sucrose $(3.00)$ & 8.47 \\
\hline 3 & 100 & Tagatose (12.96) + Fructose (1.44) & 8.28 \\
\hline 4 & 0 & Sucrose (12.00) & 8.37 \\
\hline \multicolumn{4}{|c|}{ ANOVA } \\
\hline SEm. & & 0.11 & \\
\hline $\mathrm{CD}$ & & 0.45 & \\
\hline Test $_{(0.05)}$ & & NS & \\
\hline $\mathrm{CV} \%$ & & 2.53 & \\
\hline
\end{tabular}


$14.4 \mathrm{~g}$ tagatose, $12.0 \mathrm{~g}$ sucrose, blend of $10.8 \mathrm{~g}$ tagatose $+3.0 \mathrm{~g}$ sucrose and blend of $12.96 \mathrm{~g}$ tagatose $+1.44 \mathrm{~g}$ fructose per $100 \mathrm{ml}$ Lassi as sweeteners. The samples of Lassi were evaluated for overall acceptability by a panel of experienced judges. Average results of overall acceptability from four replications are presented in Table 5.

The overall acceptability score of Lassi prepared using different sweetener was in the order of tagatose + sucrose $>$ tagatose alone $>$ sucrose alone $>$ tagatose + fructose. However, the overall acceptability score of Lassi in all the four sweeteners was highly acceptable $(>8)$.

The statistical analysis of data revealed that use of tagatose alone (@14.4 g/100 ml), blend of tagatose + sucrose (@10.8+3.0 g/100 ml), blend of tagatose + fructose (@12.96+1.44 g/100 ml) and sucrose alone (@ $12 \mathrm{~g} / 100 \mathrm{ml}$ ) as sweetener in preparation of Lassi had no significant effect on overall acceptability score of Lassi. The overall acceptability score of Lassi was statistically at par in all the four cases.

The results suggested that substitution of sucrose in Lassi by tagatose alone, blend of tagatose and sucrose or blend of tagatose and fructose had no negative effect of acceptability of Lassi. Rather there was some improvement in acceptability of Lassi upon use of tagatose alone or its blend with sucrose as sweetener.

\section{Shelf-life of Lassi}

For shelf-life evaluation only Lassi prepared using tagatose alone and sucrose alone as sweeteners were included, since these were two extreme cases among four types of sweeteners. Total three replications were conducted. Lassi was prepared using $14.4 \mathrm{~g}$ tagatose per $100 \mathrm{ml}$ and that using $12 \mathrm{~g}$ sucrose per $100 \mathrm{ml}$. Samples of Lassi were prepared, filled in PET bottles and stored in refrigerator at $6^{\circ} \pm 1^{\circ} \mathrm{C}$. The fresh (on 0 day) samples were analyzed for overall acceptability and acidity. Changes in overall acceptability and acidity of Lassi were monitored during storage on every day (i.e. at an interval of $24 \mathrm{~h}$ ), till their overall acceptability reached in vicinity of 6.0 score.

\section{Changes in overall acceptability score of Lassi during} storage

The overall acceptability score of Lassi was determined through sensory evaluation by a panel of experience judges using 9 point hedonic score. Total three replications were conducted. Results of the study along with their statistical analysis are presented in Table 6.

Table 6: Overall acceptability score of Lassi during storage on storage

\begin{tabular}{|c|c|c|c|}
\hline \multirow{2}{*}{ S1. No. } & \multirow{2}{*}{$\begin{array}{l}\text { Storage } \\
\text { period (days) }\end{array}$} & \multicolumn{2}{|c|}{ Acceptability score (out of 9) } \\
\hline & & Tagatose & Sucrose \\
\hline 1. & 0 & 8.71 & 8.71 \\
\hline 2. & 1 & 8.60 & 8.55 \\
\hline 3. & 2 & 8.55 & 8.48 \\
\hline 4. & 3 & 8.10 & 8.14 \\
\hline 5. & 4 & 7.79 & 7.90 \\
\hline 6. & 5 & 7.62 & 7.55 \\
\hline 7. & 6 & 7.29 & 7.29 \\
\hline 8. & 7 & 6.98 & 7.00 \\
\hline \multicolumn{4}{|c|}{ ANOVA } \\
\hline & $\begin{array}{l}\text { Type of } \\
\text { sweetener }\end{array}$ & Storage period & $\begin{array}{l}\text { Sweetener } \times \\
\text { Storage }\end{array}$ \\
\hline SEm. & 0.022 & 0.044 & 0.062 \\
\hline $\mathrm{CD}$ & - & 0.200 & - \\
\hline Test $_{(0.05)}$ & NS & * & NS \\
\hline $\mathrm{CV} \%$ & 1.35 & & \\
\hline
\end{tabular}

The overall acceptability score of the fresh sample of Lassi prepared using tagatose alone as a sweetener was 8.71 and that prepared using sucrose alone was also 8.71 . On seventh day of storage the acceptability score of Lassi prepared using tagatose decreased to 6.98 and that prepared using sucrose decreased to 7.00. The results revealed that on seventh day of the storage the Lassi prepared using the tagatose as a sweetener and that prepared using sucrose were very well acceptable in sensory evaluation.

Comparison between the two types of sweeteners suggested that the acceptability scores of both the Lassi were statistically at par when fresh, as well as, during each interval of the storage and at the 
end of the storage statistically remained at par. The results suggested that type of sweetener used had no statistically significant effect on acceptability score both the Lassi.

On the other hand comparison between different intervals of storage reviled that the storage period had significant effect on overall acceptability score of both the Lassi. The acceptability score of both the Lassi started decreasing significantly from initial period. The rate of decline was faster during the initial period up to 3 days, but became relatively slower at the latter stage.

The acceptability score of the Lassi decreased at almost at the similar rate during storage, irrespective of the sweetener used. Thus, stability of Lassi during the storage was not dependent on type of sweetener. This was also evident from the interaction effect between sweetener and storage period, which was non-significant.

\section{Changes in acidity of Lassi during storage}

The acidity of Lassi was determined by titration method. Total three replications were conducted. Results from the study along with their statistical analysis are presented in Table 7.

Acidity of the fresh sample of Lassi prepared using tagatose alone as a sweetener was 0.73 per cent. Similarly, acidity of the fresh sample of Lassi prepared using the sucrose alone as a sweetener was also 0.73 per cent. On seventh day of the storage acidity of Lassi prepared using tagatose increased to 0.74 per cent and that prepared using sucrose increased to 0.75 per cent. Thus, acidity of Lassi was at normal level on seventh day of the storage.

Comparison between the two types of sweeteners, the acidity of both the Lassi were statistically at par when fresh, as well as, during each interval of the storage and at the end of the storage. The results suggested that type of sweetener used in preparation had no statistically significant effect on acidity both the Lassi.

On the other hand comparison between different intervals of storage reviled that the storage period acidity of both the Lassi increased during the storage. acidity of both the Lassi increased during the storage. However, increase in acidity of Lassi from tagatose was not statistically significant. Whereas, there was statistically significant increase in acidity of Lassi from sucrose was noticed during the storage.

Table 7: Acidity of Lassi during storage when prepared using different sweeteners

\begin{tabular}{|c|c|c|c|}
\hline \multirow{2}{*}{ S1. No. } & \multirow{2}{*}{$\begin{array}{l}\text { Storage period } \\
\text { (days) }\end{array}$} & \multicolumn{2}{|c|}{ Acidity (\% lactic acid) } \\
\hline & & Tagatose + sucrose & Sucrose \\
\hline 1 & 0 & 0.73 & 0.73 \\
\hline 2 & 1 & 0.73 & 0.74 \\
\hline 3 & 2 & 0.73 & 0.74 \\
\hline 4 & 3 & 0.73 & 0.74 \\
\hline 5 & 4 & 0.73 & 0.74 \\
\hline 6 & 5 & 0.74 & 0.74 \\
\hline 7 & 6 & 0.74 & 0.74 \\
\hline 8 & 7 & 0.74 & 0.75 \\
\hline 9 & 8 & 0.74 & 0.75 \\
\hline \multicolumn{4}{|c|}{ ANOVA } \\
\hline & $\begin{array}{l}\text { Type of } \\
\text { sweetener }\end{array}$ & $\begin{array}{l}\text { Storage } \\
\text { period }\end{array}$ & $\begin{array}{l}\text { Sweetener } \\
\times \text { Storage }\end{array}$ \\
\hline SEm. & 0.005 & 0.002 & 0.006 \\
\hline $\mathrm{CD}$ & - & 0.010 & - \\
\hline Test $_{(0.05)}$ & NS & * & NS \\
\hline $\mathrm{CV} \%$ & 1.49 & & \\
\hline
\end{tabular}

In both the sweeteners the acidity of the Lassi increased at almost at the similar rate during storage, irrespective of the sweetener used. Thus, rise in acidity of Lassi during the storage was not dependent on type of sweetener. This was also evident from the interaction effect between sweetener and storage period, which was non-significant.

No report is available in the literature regarding shelf life of Lassi prepared using tagatose as a sweetener. Therefore, effect sucrose substitution in Lassi with tagatose could not be compared with the literature.

Lassi can be stored up to 7 days at $5^{\circ} \mathrm{C}$ without any significant change in its sensory qualities (Ranganadham et al. 2016). Pawar et al. (2010) found shelf life of 5 days on storage at $5^{\circ} \mathrm{C}$. Whereas, Krishna et al. (2019) reported that control sample of 
Lassi was acceptable up to 12 days, at refrigerated temperature $\left(4 \pm 1^{\circ} \mathrm{C}\right)$. Therefore, shelf life of Lassi obtained in present study was in general agreement with that reported in the literature.

The results of the study on shelf-life of Lassi and their statistical analysis, as discussed above, suggested that substitution of sucrose by tagatose as a sweetener had no adverse effect on shelf-life of the Lassi.

Therefore, findings of the study entailed to conclude that sucrose can be successfully substituted in Lassi by tagatose alone or blend of tagatose with fructose as an adjunct sweeter.

\section{REFERENCES}

Aneja, R.P., Mathur, B.N., Chandan, R.C. and Banerjee, A.K. 2002. Technology of Indian Milk Products. Dairy India Yearbook, Delhi, India.

Bagal, S.G., Chavan, K.D. and Kulkarni, M.B. 2007. Studies on preparation of Lassi from high acid cow milk. Asian J. Dairy Food Res., 26: 80-84.

Bertelsen, H., Andersen, H. and Tvede, M. 2001. Fermentation of d-tagatose by human intestinal bacteria and dairy lactic acid bacteria. Microbial Ecol. Health Disease, 13(2): 87-95.

Bhoir, K.R., Gubbawar, S.G., Shelke, R.R., Nage, S.P. and Sakate, S.B. 2012. Physico-chemical properties of Lassi sold in Akola market. Res. J. Animal Husb. E Dairy Sci., 3(1): 1720.

BIS. 1981. Handbook of Food Alalysis, Part XI, Dairy Products. Bureau of Indian Standards, Manak Bhawan, 9, Bahadur Shah Zafar Marg, New Delhi.

Davis, E.A. 1995. Functionality of sugars: Physicochemical interactions in foods. Am. J. Clinical Nut., 62(1): 170S-177S.

De, S. 2001. Outlines of Dairy Technology (First). Oxford University Press, New Delhi.

Deshpande, H.W., Phulari, S.S. and Katke, S.D. 2020. Studies on process standardization and quality evaluation of flavored Lassi. Int. J. Curr. Microbiol. Appl. Sci., 9(9): 22892296.

Dixit, N.K., Aktar Hossain, S.K., Bharti, B.K., Singh, S.S. and Mishra, S. 2018. Development of Lassi using whey and moringa powder. Int. J. Curr. Microbiol. Appl. Sci., 7(11): 602-612.

FDA. 2011. Agency Response Letter GRAS Notice No. GRN 000352 [WebContent]. Center for Food Safety and Applied Nutrition. https://wayback.archive-it. org/7993/20171031025622/https://www.fda.gov/Food/ IngredientsPackagingLabeling/GRAS/NoticeInventory/ ucm245241.htm (accessed on 09-01-2016)
Fujimaru, T., Park, J. H. and Lim, J. 2012. Sensory characteristics and relative sweetness of tagatose and other sweeteners. J. Food Sci., 77(9): S323-S328.

FSSAI. 2019. Compendium_Food_Additives_Regulations_ 29_03_2019.pdf

Hutchings, S.C., Low, J.Y.Q. and Keast, R.S.J. 2019. Sugar reduction without compromising sensory perception. An impossible dream? Critical Revi. Food Sci., \& Nutri., 59(14): 2287-2307.

Kaur, I., Chawla, R., Sivakumar, S., Goel, N. and Mishra, S.K. 2019. Screening of optimized carrot pulp concentration for development of vitamin a fortified Lassi. Int. J. Pure, App. $\mathcal{E}$ Biosci., 7(4): 231-237.

Khupse, S.M., Zinjarde, R.M., Atkare, V.G., Monali, M. and Sose, V.S. 2017. Utilization of honey as sweetener for the preparation of cow milk Lassi. J. Soils \& Crops, 27(1): 208211.

Kim, P. 2004. Current studies on biological tagatose production using l-arabinose isomerase: A review and future perspective. Applied Microbiol. Biotechnology, 65(3): 243-249.

Krishna M., Venkateshaiah, B.V. and Prabha, R. 2019. Development of long shelf-life probiotic Lassi. Asian J. Dairy Food Res., 38(4): 315-317.

Levin, G.V., Zehner, L.R., Saunders, J.P. and Beadle, J.R. 1995. Sugar substitutes: Their energy values, bulk characteristics, and potential health benefits. Am. J. Clinical Nutr., 62(5): 1161S-1168S.

Levin, G.V. 2002. Tagatose, the new GRAS sweetener and health product. J. Medicinal Food, 5(1): 23-36.

Lu, Y., Levin, G.V. and Donner, T.W. 2008. Tagatose, a new antidiabetic and obesity control drug. Diabetes, Obesity $\mathcal{E}$ Metabolism, 10(2): 109-134.

Luecke, K.J. and Bell, L.N. 2010. Thermal stability of tagatose in solution. J. Food Sci., 75(4): C346-C351.

Martí, N., Funes, L., Saura, D. and Micol, V. 2008. An update on alternative sweeteners. AgroFOOD Industry Hi-Tech, 110.

Mule, S.M., Jadhav, S.R., Kadam, S.S., Dandekar, V.S. and Ramod, S.S. 2018. Low fat Lassi prepared by incorporation of lemon grass (Cymbopogon citratus L.) extract. Asian J. Dairy \& Food Res., 37(1): 22-25.

Pallavi, R., Shree, R., Devaki, C.S. and Naik, S. 2020. Development of nutrient rich Lassi using different fruit pulp. Int. J. Sci., Technol/ \& Mgt., 11(1).

Patel, A.M., Hati, S., Mehta, B.M. and Aparnathi, K.D. 2021. Optimization of sucrose substitution of in Lassi by tagatose as a sweetener. Int. J. Curr. Microbiol. Appl. Sci., (InPress)

Pawar, B.K., Chaure, R.M., Choudhari, D.M. and Kamble, D.K. 2010. Effect of nisin on shelf-life of Lassi. J. Dairying, Foods \& Home. Sci., 29(2): 79-85. 
Ranganadham, M., Sathish Kumar, M.H., Devraja, H.C. and Garg, F.C. 2016. Traditional Dairy products. https://www. agrimoon.com/wp-content/uploads/TRADITIONALDAIRY-PRODUCTS-1.0.pdf (03-05-21).

Ranjan, S., Ranvir, S. and Balasubramanyam. 2015. Process optimization for production of Lassi by incorporation of concentrated and lactose hydrolyzed whey. Proceedings of IRF International Conference, $20^{\text {th }}$ December 2015, New Delhi, India, ISBN: 978-93-85832-81-9 https://www.digitalxplore. org/up_proc/pdf/196-145067873743.pdf (08-06-21).

Shuwu, M.P, Rangann, B.A., Suresha, K.B. and Veena, R. 2011. Development of value added Lassi using honey. Mysore J. Agric. Sci., 45(4): 757-763.

Skytte, U.P. 2006. Tagatose. In: Helen Mitchell (Ed.), Sweeteners and Sugar Alternatives in Food Technology (pp. 262-294). Blackwell Publishing Ltd., 9700 Garsington Road, Oxford OX4 2DQ, UK.

Steel, R.G.D. and Torrie, J.H. 1980. Principles and procedures of statistics. A biometrical approach, $2^{\text {nd }}$ Edition, McGrawHill Book Company, New York.

Streak, R. 2015. Consumer attitudes on sweeteners changing. Posted in Food Business News. https://www. foodbusinessnews.net/articles/6528-consumer-attitudeson-sweeteners-changing (Accessed on 05-05-2021)

Upadhyay, S., Parimita and Kumar, P. 2017. Preparation of carrot Lassi. Pharma Innovation J., 6(8): 302-305.

Vastenavond, C.M., Bertelsen, H., Hansen, S.J., Laursen, R.S.,
Saunders, J. and Eriknauer, K. 2012. Tagatose (D-tagatose), In "Alternative Sweeteners" (Lyn O'brien Nabors Ed.). CRC Press, Taylor \& Francis Group, 6000 Broken Sound Parkway NW, Suite 300, Boca Raton, FL 33487-2742, pp. 197-222.

Venema, K., Vermunt, S.H.F. and Brink, E.J. 2005. D-Tagatose increases butyrate production by the colonic microbiota in healthy men and women. Microbial Ecol. Health $\mathcal{E}$ Disease, 17(1).

WHO. 2017. Incentives and disincentives for reducing sugar in manufactured foods: An exploratory supply chain analysis. A set of insights for Member States in the context of the WHO European Food and Nutrition Action Plan 2015-2020. https://www.euro.who.int/_data/assets/pdf file/0004/355972/Sugar-report_ WHO_107773_updatedand-revised-Dec-2017.pdf (01-01-2021)

Wichchukit, S. and O'Mahony, M. 2015. The 9-point hedonic scale and hedonic ranking in food science: Some reappraisals and alternatives: The 9-point hedonic scale in food science. J. Sci. Food \& Agri., 95(11): 2167-2178. 